\title{
GAIA Preterm Birth Level of Diagnostic Certainty Terminology
}

National Cancer Institute

\section{Source}

National Cancer Institute. GAIA Preterm Birth Level of Diagnostic Certainty Terminology. NCI Thesaurus. Code C126855.

A subset of terminology related to preterm birth, developed by the Global Alignment of Immunization safety Assessment in pregnancy consortium to aid in monitoring and improving fetal and maternal outcomes. 